International Journal of Advanced Chemistry, 9(2)(2021) 99-102
International Journal of Advanced Chemistry
SPC
Website: www.sciencepubco.com/index.php/IJET
Research paper

\title{
Analysis of Herbicides Residues of Farmland Soil Samples in Some Selected Villages from Pankshin Local Government Area, Plateau State, Nigeria
}

\author{
T. M Gudam ${ }^{1}$ *, M. A Shibdawa ${ }^{1}$, I. Y Chindo ${ }^{1}$, C. W Lungfa ${ }^{1}$ \\ ${ }^{1}$ Department of Chemistry, Abubakar Tafawa Balewa University Bauchi, Bauchi state Nigeria \\ *Corresponding author E-mail: gudamf@gmail.com
}

\begin{abstract}
Most recently, there has been an increase in the use of herbicides to control weeds by farmers in Pankshin Local Government Area (LGA), Plateau State. The use of herbicides in farming activities has significantly provided more hope and assurance for sustainable food security in most countries of the world as bumper harvest have always been recorded.in its usage however the residues of the herbicides after successive accumulation by the years could be a threat to humans and other non-target organisms after they have performed their primary roles. From an interview with the farmers it was discovered that glyphosate, paraquat dichloride and 2,4-dichlorophenoxy acetic acid are mostly used within the study area which are hazardous and should be handled with utmost care. Soil samples were obtained from Bumnan, Bwarak, Larpya and control. The samples were pretreated and subjected to the following analysis: Extractions, crystallization and recrystallization with the aid of acetone, dichloromethane, hexane and methanol as solvents. Physicochemical properties of the soil samples were determined and the following range of results were obtained: $\mathrm{pH} 5.2-5.3, \%$ organic matter 4.02-8.23, EC 10-50 $\mu$ S/cm, residual moisture 0.5-3.0\% and CEC $16.52-29.63 \mathrm{cmolKg}-1$. GC analysis was carried out on the crystals and extracts to determine the herbicides concentrations and the following results were obtained in mg/kg: Bumnan -0.005 and 0.026, Bwarak- 0.004 and 0.008, Larpya- 0.015 and 0.033 and control 0.002 and 0.007 concentrations of 4, 4- bipyridine and 2,4-diphynoxyacetic acid respectively.
\end{abstract}

Keywords: Pesticides; Herbicides; Glyphosate; 4, 4-bypyridine and 2, 4-Dichlorophenoxy Acetic Acid.

\section{Introduction}

Science and technology has played a great role in developing methods and mechanisms to enhance agricultural activities. Nigeria among many developing countries has recently adopted some of these methods which include the use of pesticides/herbicides. The use of pesticides in farming activities has significantly provided more hope and assurance for sustainable food security in most countries of the world. However, the residues of the pesticides/herbicides could be a threat to human beings and other non-target organisms after they have performed their primary roles. (Gushit et al. 2013). It was reported that only one percent (1\%) of sprayed pesticides applied are often effective while ninety-nine percent ( $99 \%$ ) of the pesticides are released to non- target soils, water bodies, atmosphere and finally absorbed by almost every organism in or around that environment. (Zhang et al. 2011).

According to World health organization (WHO) "any substance or mixture of substances in food for man or animals resulting from the use of a pesticide and includes any specified derivatives, such as degradation and conversion products, metabolites, reaction products, and impurities that are considered to be of toxicological significance" are defined as herbicide/ pesticide residues. Due to this toxicological significance, there is a need to check it level in the environment so as to maintain a healthy environment.

\section{Materials and methods}

Chemicals of analytical grade were used in the preparation of reagents and extraction of samples. Distilled water was used throughout the analysis. Shimadzu Japan, GC-ECD-QP2010 PLUS was used for the analysis.

The study area comprises of villages located at the northern part of Pankshin LGA of Plateau state, Nigeria which are known for farming activities and grow crops like maize, rice, sweet potatoes, groundnuts etc. The soil samples were collected within the depth range of 0$15 \mathrm{~cm}$ from the sampling areas as described by Opelu et al., (2010) and UNEP (2007) this was carried out in September ending before harvest around 10:00 am to 3:30 pm. A global positioning system (GPS) was used to record the coordinate position of places where all the samples were collected which are: Bumnan with the GPS location: $9^{\circ} 26^{\prime} 32^{\prime \prime} \mathrm{N}, 9^{\circ} 20^{\prime} 11^{\prime \prime} \mathrm{E}$; Bwarak latitude $9^{\circ} 26^{\prime} 58^{\prime \prime} \mathrm{N}$, longitude $9^{\circ}$ 20'34” E and Larpiya latitude $9^{\circ} 27^{\prime} 5^{\prime}$ N , longitude $9^{0} 21^{\prime} 34^{\prime \prime} \mathrm{E}$.

These locations were captured in the map in figure 1 below: 


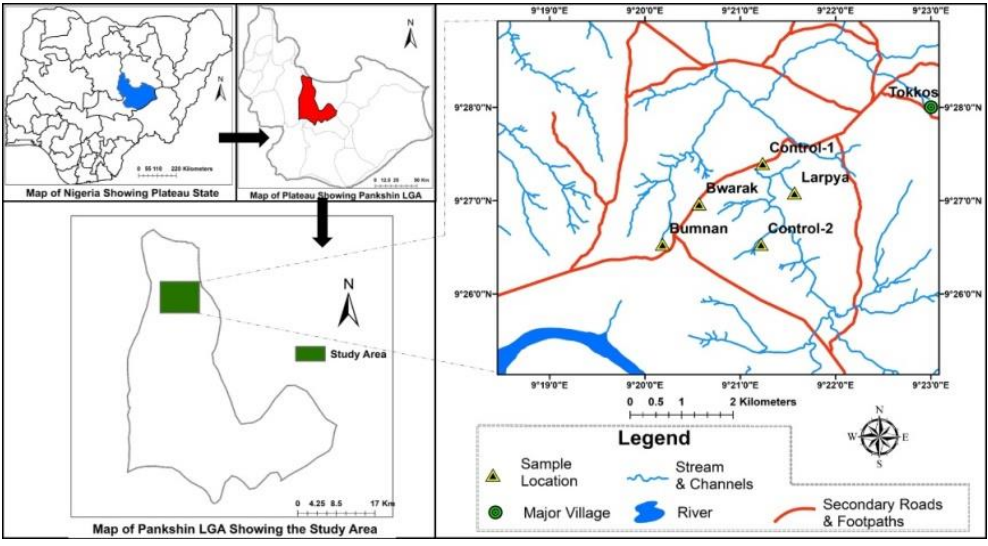

Fig. 1: Map of the Study Area.

The samples were air-dried and sieved through a No. $0.5 \mathrm{~mm}$ brass sieved and refrigerated at $4^{\circ} \mathrm{C}$ ready for further analysis. A method modified by Gushit (2014).

Moisture content was determined using a method described by Opelu et al., (2010). pH was determined using a method described by Adeleye (2005). Organic matter was determined using the Loss on ignition method. Texture was determined using a method described by Ibitoye (2000) and adopted by Gushit (2014) employing the use of a textual triangle. Electrical conductivity (EC) of the soil sample was determined using a conductivity meter. Cationic exchange capacity (CEC) was determined using method described by Ibitoye (2000) The extraction of residual pesticides from the soil samples was done using the method adopted and described by Gushit (2014). The soils samples were extracted by the solvent partition techniques using the separating funnel. $50 \mathrm{~g}$ of the samples was soaked in $30 \mathrm{ml}$ of hexanewashed water (HWW) for 30 minutes. $150 \mathrm{ml}$ acetone was then added to the mixture and before shaking it with a shaker for 1 hour. The resulting solution was transferred into a separating funnel containing $200 \mathrm{ml}$ hexane and $650 \mathrm{ml}$ hexane-wash water before shaking it for another 10-20 min. The hexane extract was washed three times with HWW and dried by passing it through anhydrous sodium sulphate. It was then concentrated to $5 \mathrm{ml}$ using the rotary evaporator. The cleaning of the extract was done by setting a column packed with $6 \mathrm{~g}$ of 60 mesh sized silica gel topped with $2 \mathrm{~cm}$ of anhydrous sodium sulfate and eluting with hexane and dichloromethane, both collected as a single fraction. The extract was finally allowed to evaporate and packed in sample bottles for Gas Chromatographic (GC) analysis.

\section{Result and discussion}

\subsection{Physico-chemical properties of soil samples}

In Table 1 below are the results of some physico-chemical parameters of soil taken from selected farmlands at Bumnan, Bwarak, Larpya and Control locations in Pankshin LGA, Plateau State. These parameters include pH, Organic matter, Electrical conductivity, Residual moisture and Temperature.

Table 1: Physico-Chemical Properties of Soil Samples Taken from Selected Farmlands in Pankshin LGA, Plateau State

\begin{tabular}{llllll}
\hline Soil samples taken from & $\mathrm{pH}$ & Organic Matter & Electrical conductivity & Residual moisture & Temperature \\
\hline Bumnan & 5.2 & 5.08 & 10 & 1.5 & 23.9 \\
Bwarak & 5.3 & 4.02 & 20 & 0.5 & 23.9 \\
Larpya & 5.2 & 8.23 & 30 & 3.0 & 23.9 \\
Control & 5.3 & 4.52 & 50 & 0.5 & 24.1 \\
\hline
\end{tabular}

The results obtained from the determination of the Textural composition and cationic exchange capacity of soil taken from selected farmlands at Bumnan, Bwarak, Larpya and Control, all in Pankshin LGA, Plateau State are presented in Table 2.

Table 2: Textural Composition and Cationic Exchange Capacity of Soil Taken from Selected Farmlands in Pankshin LGA, Plateau State

\begin{tabular}{lllll}
\hline Soil samples taken from & Sand & Silt & Clay & Cation Exchange Capacity \\
\hline Bumnan & 49.12 & 27.28 & 23.60 & 22.38 \\
Bwarak & 49.12 & 11.28 & 39.60 & 29.63 \\
Larpya & 53.12 & 23.28 & 23.60 & 18.91 \\
Control & 57.12 & 19.28 & 23.60 & 16.52 \\
\hline
\end{tabular}

From the physicochemical analysis, the sandy and clay - loam nature of the soil is predominant in all the farmland soils within the location. This makes the water retention capacity of the soils to be moderate and could retain the herbicide residues which may further allow for the herbicide residues absorption by plant species. The physicochemical properties of the soils are presented in table 1 and 2 . The soils $\mathrm{pH}$ values were acidic with range between 5.2 and 5.3. The temperature levels were similar in all farming locations, with the exception of the control which is higher by a degree Celsius. The $\mathrm{pH}$ and temperature of the soil samples are very similar to what was reported by Gushit et al, (2012), who reported an average temperature of $22{ }^{\circ} \mathrm{C}$ and an average $\mathrm{pH}$ value of 5.2 for other farmlands also located in Plateau state. The cationic exchange capacity (CEC) shows the highest value of $29.63 \mathrm{cmol} / \mathrm{kg}$ in Bwarak. Lower values of $16.52 \mathrm{and} 18.91 \mathrm{cmol} / \mathrm{kg}$ were recorded in soil samples from the control sites and Larpya soil respectively. This could be attributed to the clay and organic matter of the soil as reported by Gushit et al, (2012). The CEC which is principally the function of clay type and organic content is directly involved in herbicides adsorption

Johnson, (2003) have stated that it is soil properties such as these that are responsible for the extent of persistence of herbicides residues and as such play an important role in the carryover potential. While, Gushit et al. (2012), generalized that prevailing physicochemical properties of soil as those that were found in the farming locations under study, provides conditions that favours the persistence of herbicide residues. On the contrary, Hager (2012) put forward that soils samples with pH values averaging 5 should be expected to facilitate the 
herbicide degradation, if other factors do not come into play. Noting that it is soil with $\mathrm{pH}$ of 7.0 or higher which would support the persistence of herbicides for longer period, notwithstanding their rate of hydrolysis is retarded with increasing $\mathrm{pH}$.

\subsection{Residual herbicide concentration of soil samples}

From the chromatographic analysis using Gas Chromatography-Electronic Capture Detector (GC-ECD), the Concentrations of Herbicide residues that were present in the soil samples taken from selected farmlands at Bumnan, Bwarak, Larpya and Control locations in Pankshin LGA, Plateau State, are presented in Table 3.

Table 3: Concentration of Herbicide Residues in Soil Samples Taken from Selected Farmlands in Pankshin LGA, Plateau State

\begin{tabular}{llll}
\hline Soil samples taken from & Herbicides & Retention time $(\mathrm{min})$ & $\mathrm{Concentration}\left(\mathrm{mg} / \mathrm{Kg} \times 10^{-3}\right)$ \\
\hline \multirow{3}{*}{ Bumnan (B) } & 4,4 -bipyridine & 10.454 & $05.00 \pm 0.01$ \\
& 2,4 -diphenoxyacetic acid & 12.854 & $26.00 \pm 0.00$ \\
& Glyphosate & BDL & BDL \\
Bwarak (M) & 4,4 -bipyridine & 10.449 & $04.00 \pm 0.00$ \\
& 2,4 -diphenoxyacetic acid & 12.844 & $08.00 \pm 0.01$ \\
& Glyphosate & BDL & BDL \\
Larpya (L) & 4,4 -bipyridine & 10.444 & $15.00 \pm 0.00$ \\
& 2,4 -diphenoxyacetic acid & 12.873 & $33.00 \pm 0.00$ \\
Control (C) & Glyphosate & BDL & BDL \\
& 4,4 -bipyridine & 10.439 & $02.00 \pm 0.00$ \\
& 2,4 -diphenoxyacetic acid & 12.854 & $07.00 \pm 0.01$ \\
\hline
\end{tabular}

$\mathrm{BDL}=$ Below Detection Limit; Values Are \pm Standard Deviation $(\mathrm{N}=3)$.

The presence of herbicides in soil samples were confirmed by comparing the standard chromatogram with the sample chromatogram. According to the results obtained, two herbicides residues were detected in the samples. The detected herbicides were 2,4 -D and 4,4 bipyrindine (paraquat dichloride). The data obtained from this research were subjected to statistical analysis using one way ANOVA the result shows that there is no significant difference in the values of both herbicide residues in the soil samples at 95 percent confidence level Glyphosate was not detected in any of the soil samples that were analyzed. This could be because of it solubility in water. (Hamid et al., (2011) have reported that glyphosate is soluble in water up to $12 \mathrm{~g} / \mathrm{L}$ at room temperature. This could explain why glyphosate was below detection limit in all the soil samples given that the physicochemical parameters of the soil samples were similar. (Gushit et al., 2012) has also recorded no value for the concentration of glyphosate in fadama and upland soils analyzed in plateau state. However, (Marjo et al., 2019) has recorded a value up to $0.90 \mathrm{mg} / \mathrm{kg}$ of glyphosate in soils. This may be attributed to the difference in the physicochemical properties of the soils and other prevailing factors.

The results of the level of 4,4 - bypiridine in all the soil samples are presented in Table 3. Among the samples analyzed, Larpya soil has the highest value of the 4,4 - bipyridine residues $(0.015 \mathrm{mg} / \mathrm{kg})$ while the control soil has the least value of the herbicide's residues $(0.002$ $\mathrm{mg} / \mathrm{kg}$ ) and similar trends was observed from the result obtained for 2, 4-D.

From the results, the mean concentration of 4, 4- bipyridine residue was lower than that of 2,4-D, and this has been attributed to photodegradation as reported by Aya and Fatimah, (2012), in conjunction with other prevailing factors. Degradation of 2, 4-D in soil is a fundamental attenuation process and is influenced by both abiotic and biological processes. Different soil constituents and interactions of microbial communities and 2, 4-D in soil play a critical role in degradation process (Boivin et al., 2005). 2, 4-D usually degrades after a few days of its application through both abiotic and biotic interactions. However, $0.62 \mathrm{mg} \mathrm{kg}^{-1}$ or $2 \%$ of applied 2,4-D exits in soil for an extended period of time and may affect the growth of sensitive crops after 9 months of 2, 4-D application (Boivin et al., 2005; Germaine et al., 2006). The presence of 2, 4-D residues for an extended period of time in soil may be due to the presence of microorganisms lacking catabolic capacity to degrade 2, 4-D or having a small population (Germaine et al., 2006).

\section{Conclusion}

Soil samples from various farmland locations were analyzed for herbicides residues level. Two among the three herbicide residues that were analyzed for were present in the soil samples. It was observed that the physicochemical properties of the soil samples analyzed were not altered by the presence of herbicide residues because the values observed from the control soil are very similar to those observed for the various treated soils and the properties of the soil are those that support agricultural activities. Though 4,4 -bypridine and 2,4 -D residues were present in all the soil samples at various concentrations, they were not present in high concentrations that can pose serious pollution effects. However it is important to educate the farmers within the locality on the hazard of these chemicals and how to properly use them so as to avoid future risk.

\section{References}

[1] Boivin, A., Amellal, S., Schiavon, M., Van Genuchten, M.T., (2005). 2,4-Dichlorophenoxyacetic acid (2,4-D) sorption and degradation dynamics in three agricultural soils. Environ. Pollution. 138, 92-99 https://doi.org/10.1016/j.envpol.2005.02.016.

[2] Germaine, K.J., Liu, X., Cabellos, G.G., Hogan, J.P., Ryan, D., Dowling, D.N., (2006). Bacterial endophyte-enhanced phyto-remediation of the organochlorine herbicide 2,4-dichlorophenoxy acetic acid. FEMS Microbiol. Ecol. 57, 302-310. https://doi.org/10.1111/j.1574-6941.2006.00121.x.

[3] Gushit S.J, Eno.O. E, Harami M. A, and Ovi J. A., (2012). The persistence of herbicides residue in fadama and upland soils in Plateau state, Nigeria. Journal of environmental science and earth science vol 2 no. 10.

[4] Gushit S.J., Eno.O. E, Harami M. A, and Chindo I. Y., (2013). Analysis of herbicides residue and organic priority pollutants in selected root and leafy vegetable crops in plateau state Nigeria. World journal of analytical chemistry vol. 1, No. 2, 23-28.

[5] Gushit S. J (2014) the risk assessment of herbicide usage, determination and remediation of their residues in soil, water and crops in plateau state, (doctoral dissertation Abubakar tafawa Balewa university Bauchi), 2014) 27-41.

[6] Hager A., (2012). Beware of the Potential of Herbicides Carry over. News Release. http://web.extension.illinois.edu/state/publications.html.

[7] Hamid A. A., Aiyelagbe, O. O., and Bologun, G. A. (2011) herbicides and Advanced natural and applied sciences 5(2): 201-213.

[8] Ibitoye, A. A., (2006). Laboratory manual on basic soil analysis. Foladave Nig. Ltd Press, Akure, Nigeria. Pp. 1-86.

[9] Johnson E., (2003). Herbicides soil residues. Agricultural and Agri-foods Canada, Scott, SK. 134-139. 
[10] Marjo H., Anna P., Kari S., and Irma S., (2019). Glyphosate residues in soil affect crop plant germination and growth. Scientific Reports 9:19653

[11] Opeolu, B. O., Adenuga, O. O., Ndakidemi, P.A. and Olujimi, O. O., (2010). Assessment of phyto-toxicity potential of lead on tomato (Lycopersicon esculentum L) planted on contaminated soil. International Journal of Physical Sciences. Vol. 5 (2). Pp. 068-073.

[12] Singh, D.K., Agarwal, H.C. (1992), Chemical release and nature of soil-bound DDT residues, J. Agric. Food Chem. 40 1713-1716. https://doi.org/10.1021/jf00021a047.

[13] Tejada, L.W.,et al. (1990), The fate of carbofuran in rice, fish and livestock farming, Journal of tropical Pest Management. $39281-287$.

[14] UNEP, (2007). Guidance for Analysis of persistent organic pollutants (POPs), UNEP Chemical branch, DTIE, March 2007.

[15] Zhang, W., Jiang, F. and Ou J. (2011) Global Pesticide consumption and Pollution: with China as a focus. Proceeding of the International Academy of Ecology and Environmental Sciences. 1 (2): 125-144. 